\title{
NAD-Dependent Deacetylase Sirtuin-2
}

National Cancer Institute

\section{Source}

National Cancer Institute. NAD-Dependent Deacetylase Sirtuin-2. NCI Thesaurus. Code C101564.

NAD-dependent deacetylase sirtuin-2 (389 aa, $\sim 43 \mathrm{kDa}$ ) is encoded by the human SIRT 2 gene. This protein plays a role in the deacetylation of tubulin. 